\title{
Study on Composite Material Marine Propellers*
}

\author{
Toshio Yamatogi ${ }^{* *}$
}

\section{ABSTRACT}

In this study, the authors conducted mechanical property tests and the vibration characteristic tests of CFRP (carbon fiber reinforced plastics) specimens that can be adopted as new marine propeller materials. CFRP materials exhibited higher strength than NAB (nickel aluminum bronze casting) which is conventionally used as material for marine propellers. The damping ratio of CFRP materials was four times larger or more than that of NAB.

In field tests using a small fishing boat, two types of CFRP propellers were manufactured by using CF-prepreg. One propeller was laminated with CF-Fabric and another with CF-UD, to obtain a quasi-isotropic composite. These are the so-called "built-up type" as three CFRP blades were assembled in an NAB boss. An NAB propeller of the so-called "mono-block type" was also manufactured to facilitate comparison with CFRP propellers. Analyses of field test results are ongoing. In vibration tests, the damping ratios of the both types of CFRP propellers were about ten times larger than that of the NAB propeller. Cavitation which can cause erosion on the surface is a severe problem for FRP propellers. Therefore, we cavitation erosion resistances for eight kinds of FRP and an NAB were evaluated in cavitation tests using a magnetostriction ultrasonic transducer.

The cavitation erosion resistance of the NAB was much superior to that of FRP materials. However, it was found that aramid fibers on the surface of FRP can improve the erosion resistance. In order to improve the erosion resistance of FRP materials to the same level as that of NAB, the further research is necessary.

\section{INTRODUCTION}

Composite materials have some advantages such as the

\footnotetext{
* $\quad$ Received February 16,2011

** Nakashima Propeller Co., LTD., Okayama, Japan

**k The University of Tokyo, Tokyo, Japan
}

\author{
Hideaki Murayama*** \\ Takahiro Mishima**
}

higher specific strength/stiffness and the corrosion resistance compared with metallic materials. Accordingly, they are adopted in many kinds of fields such as the aircrafts, the vehicles and the wind turbines.

In the marine fields, composite materials are generally used to the hulls of boats and yachts excluding huge vessels. Recently, the studies of marine propellers are focused on the application of composite materials ${ }^{1-7}$. Composites can have advantages of high elasticity, damping and specific strength compared with metallic materials. So far, composite materials have been developed for the propellers with special vessels like war ships and submarines. In terms of the material cost, the wide usage and the progress of production technologies for composite materials can reduce the cost. Consequently, we can say that the composite materials have great potential for marine propellers.

In this study, tensile and bending tests with specimens of CFRP (carbon fiber reinforced plastics) were implemented. The strengths of CFRP are compared with that of NAB (nickel aluminum bronze casting) which is a conventional propeller material. Moreover, the damping characteristics of them were evaluated in vibration tests.

For the field test using a small fishing boat, two types of CFRP propellers were manufactured by using CF-prepreg. One propeller and another one were laminated CF-Fabric and CF-UD, respectively, to be quasi-isotropic composite. These were a so-called "built-up type" as three CFRP blades were assembled in an NAB boss. We also manufactured an NAB propeller which was a so-called "mono-block type" to compare with the CFRP propellers. The vibration test was carried out for the both type of CFRP and the NAB propellers, those modal parameters were obtained and evaluated.

Cavitation which can cause erosion on the surface is the severe problem for FRP propellers. Therefore, we evaluated the cavitation erosion resistance for eight kinds of FRP and an NAB in cavitation tests using a magnetostriction ultrasonic transducer.

The propellers made of CFRP will be evaluated the 
performance and durability as analyzing the result of the field test with the actual ship in the near future.

\section{MATERIAL TESTING}

\subsection{Specification of Specimens}

We carried out tensile and the bending tests for specimens of CFRP specimens were made as laminating prepreg materials and curing in autoclave. These prepregs were laminated to become quasi-isotropy.

Table 1 shows specification of specimens. Fabric textile is that the fibers are alternately woven orthogonal. UD textile is that the fibers are allayed uni-direction. For ply orientations and stacking sequence of specimens, Fabric-iso is $[ \pm 45 / 0,90 / \pm 45 / 0,90] 2 \mathrm{~s}, \quad$ and UD-iso is $[+45 / 0 /-45 / 90 / 90 /-45 / 0 /+45] 2$ s. Density of NAB is shown under the table as reference for the vibration tests discussed below.

Table 1 Specification of specimens

\begin{tabular}{|c|c|c|}
\hline & CFRP-Fabric-iso & CFRP-UD-iso \\
\hline Fiber & Carbon & Carbon \\
\hline Textile & $\begin{array}{c}\text { Fabric } \\
\text { (cross) }\end{array}$ & $\begin{array}{c}\text { UD } \\
\text { (Uni-Direction) }\end{array}$ \\
\hline Matrix & Epoxy & Epoxy \\
\hline $\begin{array}{c}\text { Orientation } \\
\text { and stacking }\end{array}$ & $\begin{array}{c} \pm \pm 45 / 0,90 / \\
\pm 45 / 0,90]_{2 \mathrm{~s}}\end{array}$ & $\begin{array}{c}{[+45 / 0 /-45 / 90 /} \\
90 /-45 / 0 / 445]_{2 \mathrm{~s}}\end{array}$ \\
\hline Property & Quasi-isotropy & Quasi-isotropy \\
\hline Fabrication & Prepreg-autoclave & Prepreg-autoclave \\
\hline Thickness(mm) & $1.78 \pm 0.02$ & $1.95 \pm 0.02$ \\
\hline$V_{f}(\%)$ & 51.0 & 55.0 \\
\hline Density $\left(\mathrm{kg} / \mathrm{m}^{3}\right)$ & 1,490 & 1,540 \\
\hline
\end{tabular}

$\mathrm{NAB}$ (nickel aluminum bronze casting, $\mathrm{CAC703):} \mathrm{density}=7,600$ $\left(\mathrm{kg} / \mathrm{m}^{3}\right)$

\subsection{Tensile Test}

The tensile test applied to JIS K 7073. For size of specimen, the length is $200 \mathrm{~mm}$, the width is $15 \mathrm{~mm}$, and the thickness of each Fabric-iso and UD-iso is shown as Table 1. The specimens were prepared each 5 pieces. The speed of cross head of testing device was $1 \mathrm{~mm} / \mathrm{min}$. Stress-strain curves are shown in Figure 1. The stress of UD-iso appeared a yield point about $350 \mathrm{MPa}$ because of damage, and then the stress increased with the same stress curve of Fabric-iso. Figure 2 and 3 show ultimate longitudinal stress and longitudinal elastic modulus, respectively, obtained from the stress-strain curves (Figure 1). The ultimate stress and the elastic modulus for NAB are shown as a reference. Both strengths of Fabric-iso and UD-iso were almost equivalent with that of NAB. In this study, we regard the tensile strengths of Fabric-iso and UD-iso as $600 \mathrm{MPa}$ and $350 \mathrm{MPa}$, respectively, based on the test results. The strength of NAB is regarded as the proof stress of $245 \mathrm{MPa}$ in JIS.

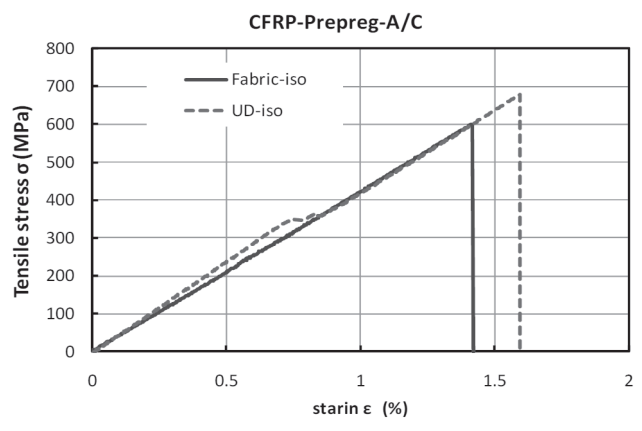

Figure 1 Tensile stress - strain curves of CFRPs

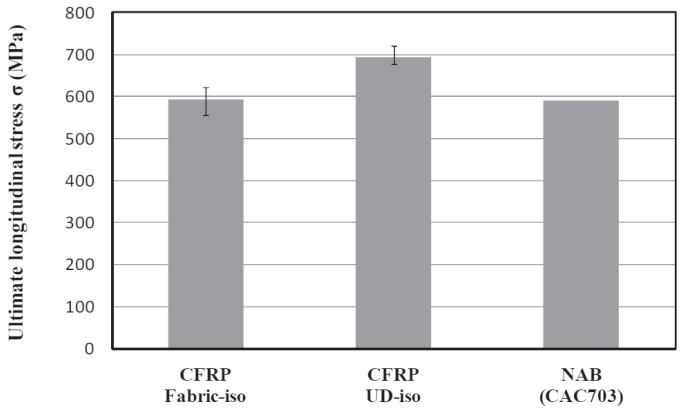

Figure 2 Ultimate longitudinal stress

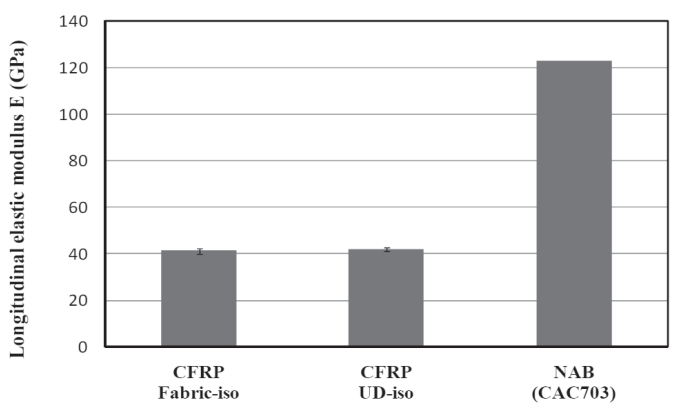

Figure 3 Longitudinal elastic modulus

\subsection{Bending Test}

The bending test applied to ASTM-D790M-86. Figure 4 shows schematic drawing of three point flexural strength test. Span of supports in this figure, $L$ is $64 \mathrm{~mm}$. For size of specimen, the length is $80 \mathrm{~mm}$, the width is $10 \mathrm{~mm}$, and each thickness of Fabric-iso and UD-iso is shown in Table 1. The specimens were prepared each 5 pieces. Measurement items were load and deflection. The speed of cross head of testing device was $5 \mathrm{~mm} / \mathrm{min}$. 
A load-deflection curve is shown in Figure 5. The flexural stress of fracture for UD material was about twice of Fabric one. Ultimate flexural stress $\sigma$ is estimated by the following equation $(\delta / L>0.1)$ :

$$
\sigma=\frac{3 P L}{2 b h^{2}}\left\{1+4\left(\frac{\delta}{L}\right)\right\}
$$

Where, $\sigma=$ ultimate flexural stress (MPa); $P=$ maximum $\operatorname{load}(\mathrm{N}) ; L=$ span of supports $(\mathrm{mm}) ; b=$ width of specimen $(\mathrm{mm}) ; h=$ thickness of specimen $(\mathrm{mm}) ; \delta=$ deflection at $P_{\max }(\mathrm{mm})$.

Next, the inclination of initial load-deformation is used and the flexural elastic modulus $E_{f}$ was estimated by the following equation:

$$
E_{f}=\frac{1}{4} \cdot \frac{L^{3}}{b \mathrm{~h}^{3}} \cdot \frac{\mathrm{P}}{\delta} \sigma
$$

Where, $P=$ maximum load $(\mathrm{N}) ; L=$ span of supports (mm); $b=$ width of specimen (mm): $P / \delta=$ linear inclination in load deflection curve $(\mathrm{N} / \mathrm{mm})$.

Figure 6 and 7 show ultimate flexural stress and flexural elastic modulus, respectively, estimated by Eqs. (1) and (2). Those values for NAB are also shown as reference. NAB is ductility and isotropic material, and its flexural strength and flexural elastic modulus were assumed to be equivalent with the tensile properties. Ultimate flexural stress (flexural strength) of Fabric-iso and UD-iso were $660 \mathrm{MPa}$ and 1100 $\mathrm{MPa}$, respectively. Both flexural strength of CFRPs were larger than that of NAB. The flexural strength of UD-iso was 1.7 times of that of Fabric-iso.

The flexural elastic modulus of Fabric-iso and UD-iso were $1 / 4$ times and $1 / 3$ times lower than that of NAB, respectively.

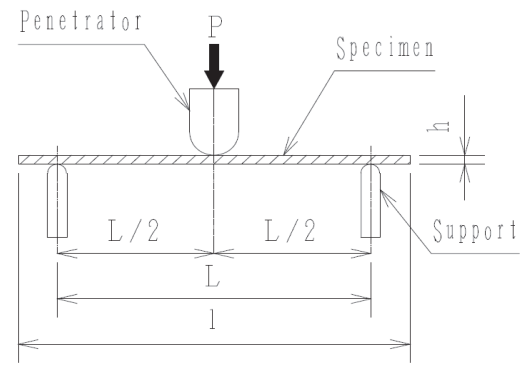

Figure 4 Schematic drawing of three point flexural strength test

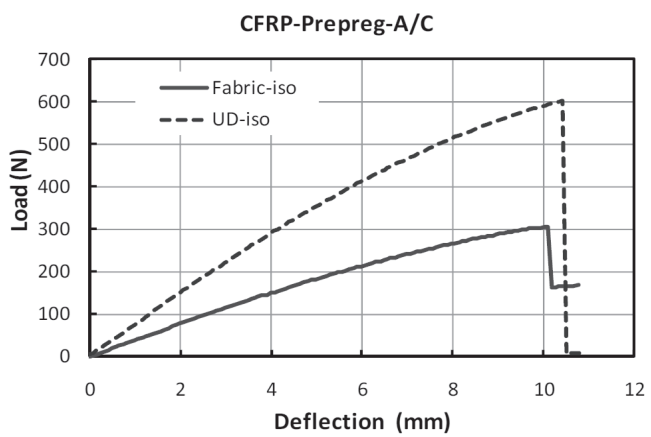

Figure 5 Load-deflection curves of CFRPs

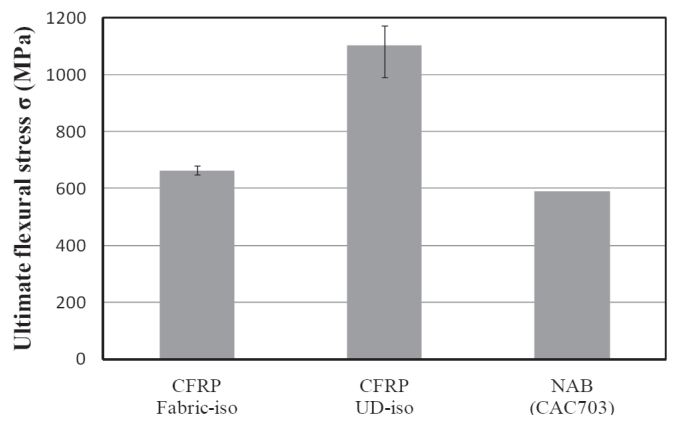

Figure 6 Ultimate flexural stress

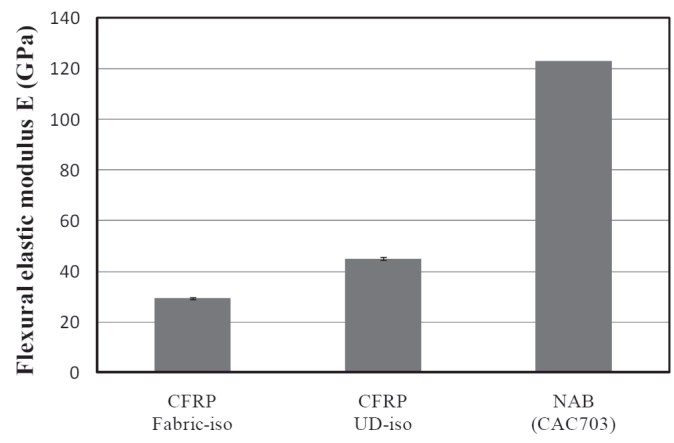

Figure 7 Flexural elastic modulus

\subsection{Vibration Test}

Here, the vibration test was carried out by center exciting method for vibration-damping property in damped composite beam of the unconstrained condition according to JIS K 7391.

The loss factor $\eta$ of the specimen was shown in Figure 8 , and damping ratio $\zeta$ was given by $\zeta=\eta / 2$. The center of the specimen was set on the edge of contact tip installed the impedance head by the instance adhesive. Excitation force and acceleration were detected at the impedance head, and the impedance (excitation force $F$ / velocity $V$ ) was obtained. The loss factor $\eta$ was calculated using half-power bandwidth method using FFT analyzer. Ideal impedance was also measured without the specimen and the contact chip to compensate the influence of those mass. The testing 
temperature was about 21 degrees Celsius.

The vibration test was conducted for two types of CFRP and one NAB as shown in Figure 8. The size of specimens, the length is $200 \mathrm{~mm}$, the width is $15 \mathrm{~mm}$ and the thickness is seen Table 3. Each CFRP specimen was prepared 5 pieces and the vibration tests were implemented using each specimen and the data was averaged. In the case of NAB, one specimen was prepared, and the measurements data were obtained 5 times and the data was averaged.

The measurement result is shown in Figure 9 and Table 2. The damping ratios of the both CFRP materials were 4 times or more compared with that of NAB. The damping property of Fabric-iso was higher than UD-iso. Here, Table 3 shows the resonance frequency (the natural frequency) calculated by following equation:

$$
f=\frac{2 \lambda_{o}^{2}}{l^{2} \pi} \sqrt{\frac{E_{f} I}{\rho b h}}
$$

Where, $f=$ resonance frequency $(\mathrm{Hz}) ; E_{f}=$ flexural elastic modulus $(\mathrm{MPa}) ; I=$ second moment of area $\left(\mathrm{m}_{4}\right) ; l=$ length of specimen $(\mathrm{m}) ; b=$ width of specimen $(\mathrm{m}) ; h=$ thickness $\mathrm{f}$ specimen $(\mathrm{m}) ; \rho=$ density $\left(\mathrm{kg} / \mathrm{m}_{3}\right) ; \lambda_{o}=$ 1.875(1st), 4.694(2nd), 7.855(3rd).

The resonance frequencies in the test agree with those estimated by Eq. (3) as shown in Tables 2 and 3.

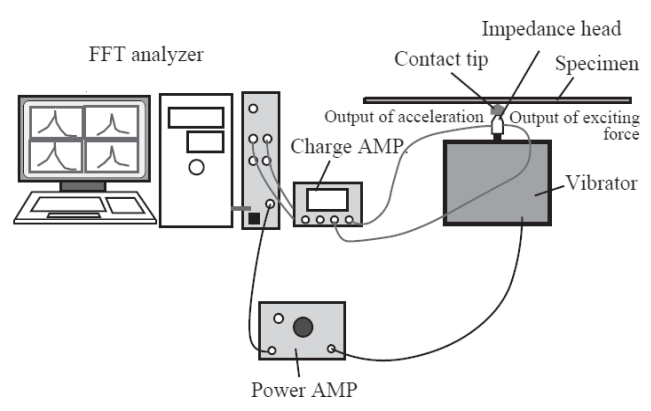

Figure 8 Measurement method for vibration-damping property in damped composite beam of unconstrained type

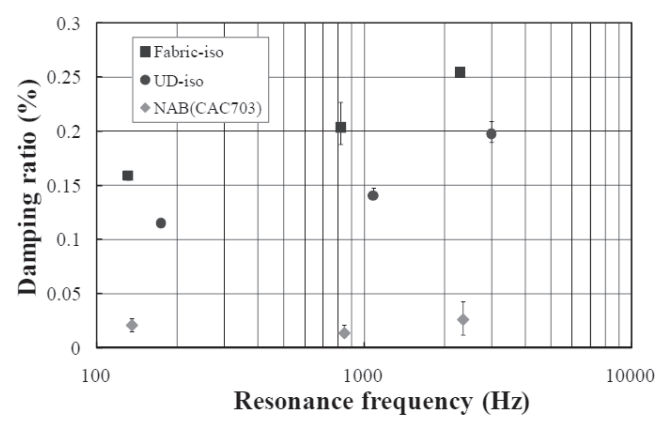

Figure 9 Damping ratio - Resonance frequency at vibration
Table 2 Result of damping ratio for each materia

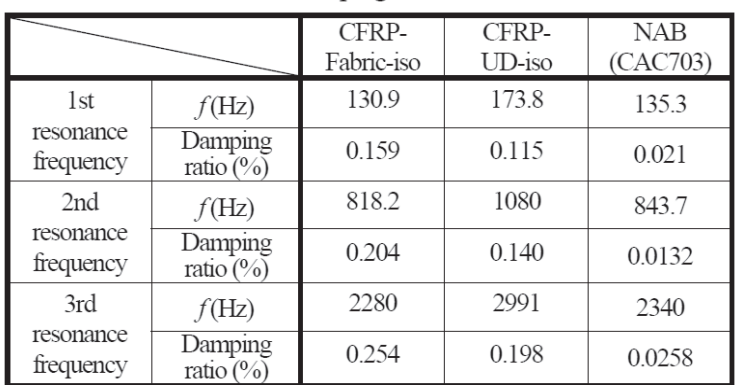

Table 3 Estimated resonance frequency

\begin{tabular}{|c|c|c|c|}
\hline & $\begin{array}{c}\text { CFRP- } \\
\text { Fabric-iso }\end{array}$ & $\begin{array}{c}\text { CFRP- } \\
\text { UD-iso }\end{array}$ & $\begin{array}{c}\text { NAB } \\
\text { (CAC703) }\end{array}$ \\
\hline Thickness $b(\mathrm{~mm})$ & 1.77 & 1.94 & 2.03 \\
\hline Elastic modulus $E(\mathrm{GPa})$ & 29.3 & 45.0 & 123 \\
\hline 1st resonance frequency $(\mathrm{Hz})$ & 126.8 & 169.0 & 131.9 \\
\hline 2nd resonance frequency $(\mathrm{Hz})$ & 794.6 & 1059 & 826.7 \\
\hline 3rd resonance frequency $(\mathrm{Hz})$ & 2225 & 2966 & 2315 \\
\hline
\end{tabular}

\section{CFRP PROPELLER}

\subsection{Specification of Ship}

We have a plan to implement field tests using an actual ship test with CFRP propellers. The ship is a small fishing boat as follows.
Gross tonnage

Loa $\times \mathrm{B} \times \mathrm{D}$

Output power

Propeller speed

Ship speed
$: 3.3 \mathrm{G} / \mathrm{T}$

$: 10.50 \mathrm{~m} \times 2.75 \mathrm{~m} \times 1.4 \mathrm{~m}$

$: 221 \mathrm{~kW} / 2600 \mathrm{~min}^{-1}(\mathrm{i}=2.58)$

$: 1008 \mathrm{~min}^{-1}$

:26 knots $(13.4 \mathrm{~m} / \mathrm{s})$

\subsection{Design of Propeller}

The CFRP propeller was designed based on existing metallic propeller of the ship above. Specification of the propeller is as follows.

$\begin{array}{ll}\text { Number of blade } Z & : 3 \\ \text { Propeller diameter } D & : 680 \mathrm{~mm} \\ \text { Propeller pitch } H & : 1120 \mathrm{~mm}(\mathrm{H} / \mathrm{D}=1.647) \\ \text { Boss diameter } B & : 136 \mathrm{~mm}(\mathrm{~B} / \mathrm{D}=0.20) \\ \text { Expanded propeller area ratio } A e & : 0.55\end{array}$

This CFRP propeller is a built-up type of 3-blades and 1boss. The structural concept is shown in Figure 10. The blades and the boss are made of CFRP and NAB, respectively, and the boss has grooves for installing the blades. The blades are inserted into the grooves from the boss's rear, and they are fixed with the retaining ring of the omission stop. 
Pressure distribution on the blade surface was obtained from lifting surface theory. By using this pressure distribution as the load condition, deformation and stress of the blade were calculated by FEM (I-DEAS 12NXm). Results of FEM analysis are shown in Figure 11, 12 and 13. The deformation in those figures is represented as 20 times of the original deformation.

Table 4 shows maximum deformation, variation of mean pitch and stress of each propeller. The amount of deformation was largest at top of the blade, and the pitch of blade was increasing to the tip. The deformation of both CFRP propellers is larger than that of the NAB propeller, the Fabric and the UD type was about 4 times and about 2.5 times of the NAB respectively. As for the variation of the pitch, the Fabric and the UD type were about 10 times and about 7 times of NAB, respectively.

However, the rate of pitch variation for the Fabric was only $0.38 \%$ (= $4.2 \mathrm{~mm}, / 1120 \mathrm{~mm}$ ). Therefore, it seems that the performance of CFRP propellers can be same as that of NAB one. The maximum von Mises stress of Fabric-iso propeller was about $1 / 6$ times of the tensile strength (590 $\mathrm{MPa}$ ) and was about 1/7 times of the flexural strength (660 $\mathrm{MPa}$ ) of Fabric-iso. The maximum stress of UD-iso propeller was about 1/4 times of the allowable strength (350MPa), and was about 1/11 times of the flexural strength (1100 MPa) of UD-iso. The maximum stress of NAB propeller was about 1/2.5 times of the proof stress (245 $\mathrm{MPa}$ ) and was about $1 / 6$ times of the ultimate longitudinal stress and proof stress (590 MPa) of NAB in JIS.

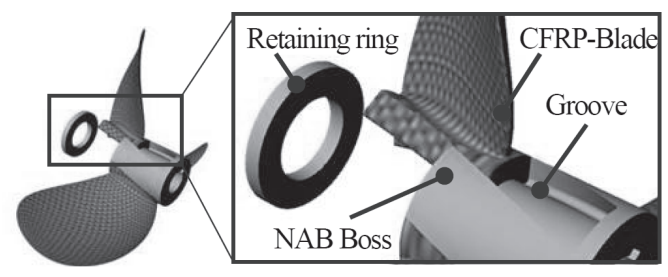

Figure 10 Concept of built-up CFRP propeller

Table 4 Result of FEM analysis for the propellers

\begin{tabular}{|l|c|c|c|}
\hline & $\begin{array}{c}\text { CFRP- } \\
\text { Fabric-iso }\end{array}$ & $\begin{array}{c}\text { CFRP- } \\
\text { UD-iso }\end{array}$ & NAB \\
\hline Max. Deformation (mm) & 7.11 & 4.63 & 1.84 \\
\hline Variation of mean pitch (mm) & 4.2 & 2.8 & 0.4 \\
\hline Max. von Mises stress (MPa) & 91.8 & 91.8 & 96.7 \\
\hline
\end{tabular}

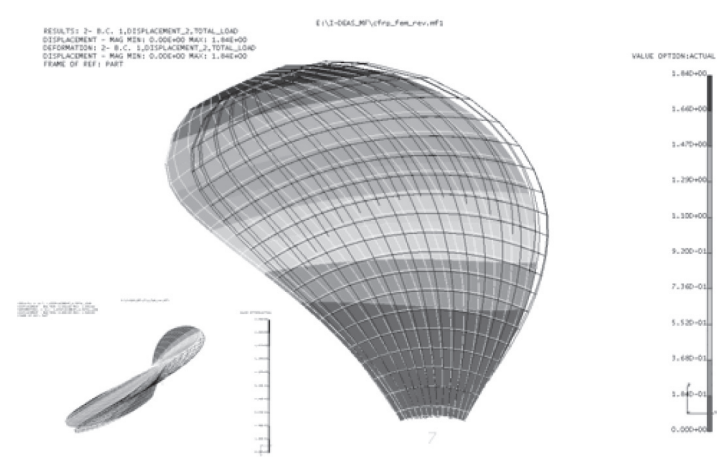

Figure 11 Deformation of NAB propeller
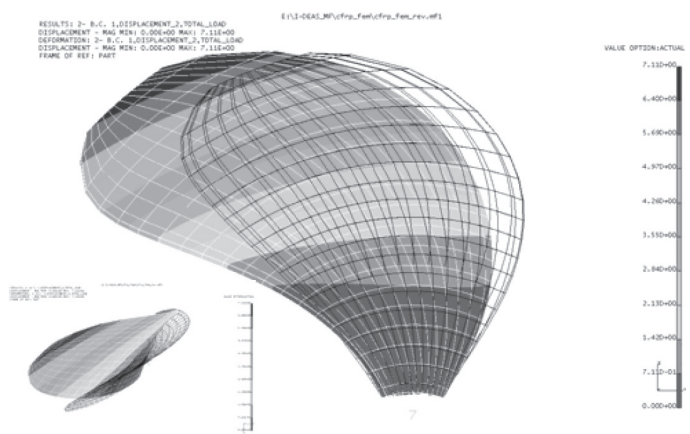

Figure 12 Deformation of Fabric-iso CFRP propeller

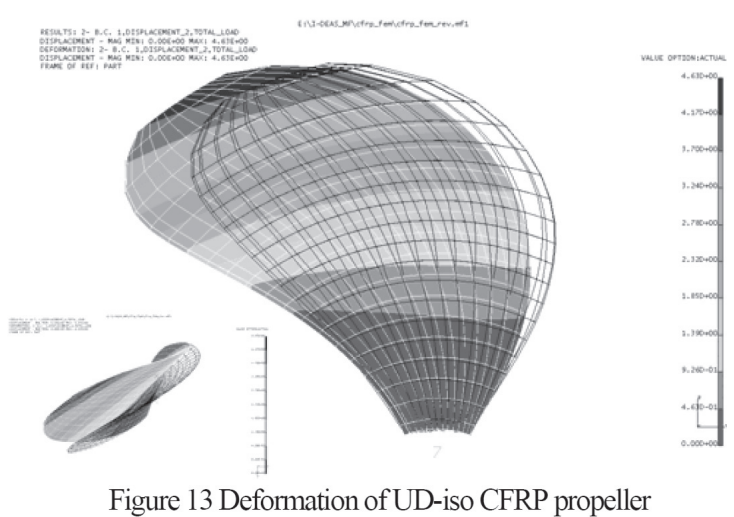

\subsection{Manufacturing of CFRP Propeller}

Two CFRP propellers were manufactured by using CF-prepreg of Fabric and UD to laminate as quasi-isotropic property. The blades and the completed built-up CFRP propeller are shown in Figure 14 and 15, respectively. The urethane resin was painted on the blades.

Inspection of visual and dimension for CFRP propellers were conducted. The surface of blades was smooth, and the dimension of propellers was in the tolerance of the super-high speed ship, and it was confirmed that they were excellent.

To compare the damping property of propeller with CFRP and $\mathrm{NAB}$, a NAB propeller was manufactured with a mono-block type and same shape as CFRP one. We have a 
plan to compare propeller performance with the NAB and the CFRP propellers in actual ship test in the near future.

The each mass of the propellers was the following: $31.6 \mathrm{~kg}$ for NAB; $15.8 \mathrm{~kg}$ for Fabric-iso type; $15.6 \mathrm{~kg}$ for UD-iso type. Both CFRP propellers were about half mass of the $\mathrm{NAB}$ one. The each moment of inertia for the propellers was the following: $0.638 \mathrm{~kg}-\mathrm{m}^{2}$ for NAB; $0.150 \mathrm{~kg}-\mathrm{m}^{2}$ for Fabric-iso; $0.154 \mathrm{~kg}-\mathrm{m}^{2}$ for UD-iso, respectively. The moment of inertia for the CFRP propellers became $1 / 4$ or less compared with that for the NAB one.

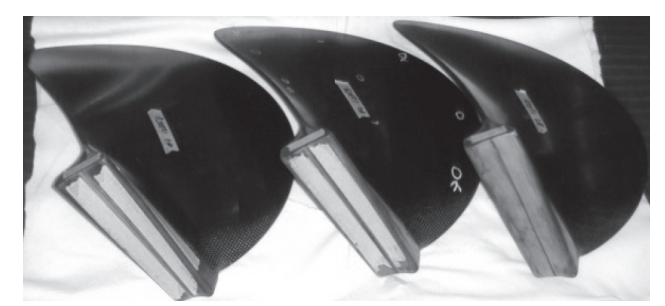

Figure 14 CFRP Blades

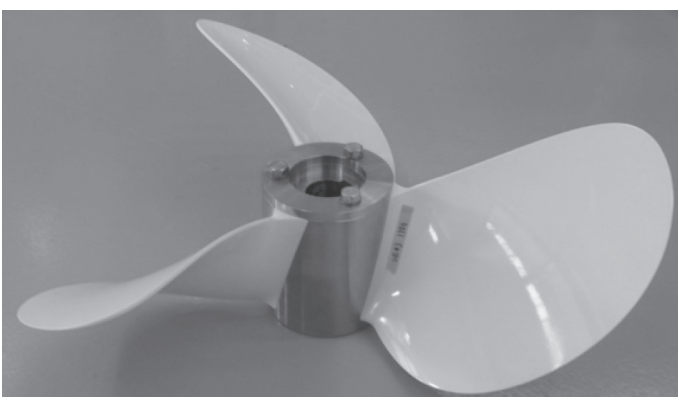

Figure 15 Complete CFRP propeller

\subsection{Vibration Characteristic Testing for CFRP Propeller}

The vibration characteristic was evaluated in the vibration test. The blades for two CFRP and one NAB propeller were excited with an impulse hammer, and examined for the modal parameter (resonance frequency, damping ratio and mode shape).

Measurement method of vibration characteristic test for the propellers and the photograph of the test condition are shown in Figure 16 and 17, respectively. Figure 18 shows that a three direction accelerometer is set on the surface of each blade by an instant adhesive. The blade was excited with the impulse hammer, and the vibration transmission characteristic (frequency response function, FRF) between the excitation point and the measurement point was measured. The measured FRF from exiting at 20 points on the each blade was processed by curve fitting, the modal parameters of the propeller were obtained.

Resonance frequency and damping ratio of each propeller in a typical mode shape are shown in Table 5. The mode shape shows the 1st-3rd of bending vibration same as section 2.3 and the 1st twist vibration in addition. The damping ratio in the 1st- 3rd resonance frequency of the bending vibration is shown in Figure 19. The following have been understood from these results.

1) For propeller vibration characterization, the various mode shapes appeared with coupled vibration of each blade. Therefore it is impossible to evaluate vibration characteristic of whole propeller by measuring the vibration mode of the blade unit only.

2) Resonance frequency of same mode shape rose in order of NAB, Fabric-iso, UD-iso. This is thought that comparable rigidity is large in this order.

3) The both damping ratio of CFRP propellers were about ten times larger than that of $\mathrm{NAB}$ propeller. For $\mathrm{NAB}$ propeller, the attenuation of the material in itself is low and it is a mono-block structure. On the other hand, CFRP material is high attenuation comparing with $\mathrm{NAB}$, in addition it is thought that CFRP propeller is built-up structure which is attenuated by friction at contact parts of the blade and the groove on the boss.

4) For CFRP propellers, there were not any clear differences though the damping ration of Fabric-iso was a little higher than that of UD-iso.

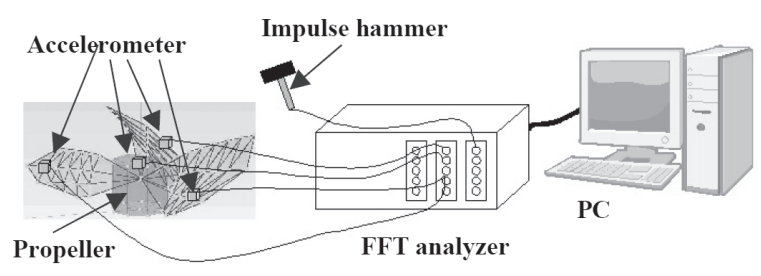

Figure 16 Measurement method for vibration-damping property in propeller

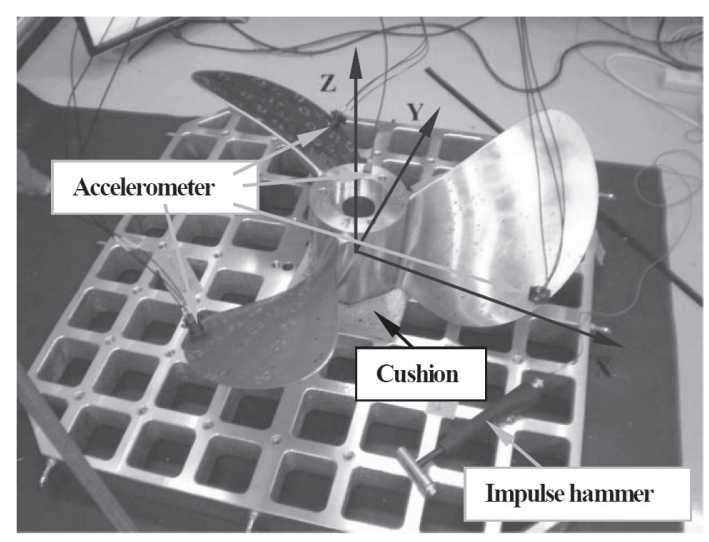

Figure 17 Photograph of the test condition 


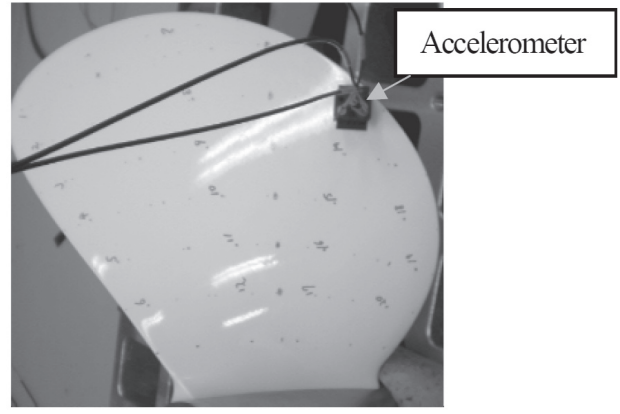

Figure 18 Setting of accelerometer on the blade

Table 5 Result of damping ratio at mode shape for each propeller

\begin{tabular}{|c|c|c|c|}
\hline & Mode shape & $\begin{array}{c}\text { Resonance } \\
\text { frequency (Hz) }\end{array}$ & $\begin{array}{c}\text { Damping ratio } \\
\text { (\%) }\end{array}$ \\
\hline \multirow{3}{*}{$\begin{array}{c}\text { CFRP } \\
\text { Fabric } \\
\text {-iso }\end{array}$} & 1st-bending & 306.4 & 0.286 \\
\cline { 2 - 4 } & 2nd-bending & 401.7 & 0.344 \\
\cline { 2 - 4 } & 1st - twist & 592.8 & 0.217 \\
\hline \multirow{3}{*}{$\begin{array}{c}\text { CFRP } \\
\text { UD - bending }\end{array}$} & 944.3 & 1.233 \\
\cline { 2 - 4 } iso & 1st-bending & 325.2 & 0.342 \\
\cline { 2 - 4 } & 2nd-bending & 411.5 & 0.316 \\
\hline \multirow{4}{*}{ NAB } & 3rd- twist & 605.0 & 0.333 \\
\cline { 2 - 4 } & 1st-bending & 858.4 & 0.601 \\
\cline { 2 - 4 } & 2nd-bending & 294.1 & 0.036 \\
\cline { 2 - 4 } & 1st- twist & 374.3 & 0.038 \\
\cline { 2 - 4 } & 3rd- bending & 713.9 & 0.042 \\
\hline
\end{tabular}

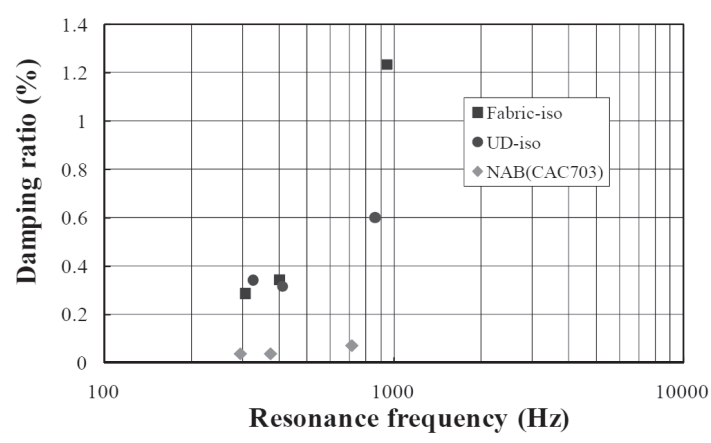

Figure 19 Damping ratio - Resonance frequency at bending vibration

\section{CAVITATION TEST}

\subsection{Test specimens}

Test specimens were of the nine types shown in Table 6 . There were three types of reinforced fibers. Those were carbon fiber (CF), glass fiber (GF) and aramid fiber (AF). For $\mathrm{CF}$, there were two types of textiles that were fabric and multi-axial, and two typs of fabrication processes that were vacuum assisted resin transfer molding (VaRTM) and prepreg autoclave method. In the results, we had three
CFRP specimens, namely CF-Fab-VaR, CF-MA-VaR, and CF-prepreg.

In the case of GF, we did not use any prepreg, so there were two specimens, namely GF-Fab-VaR and GF-MA-VaR. Then we had two specimens made of AFRP whose fabric plies were two and four, respectively. The fabrication process used for AFRP was also VaRTM. In addition, we prepared a specimen made of only epoxy resin and an $\mathrm{NAB}$ which is used for marine propellers as usual.

Table 6 Tested material

\begin{tabular}{|c|c|c|c|c|}
\hline Name & Fiber & Textile & Matix & Fabrication \\
\hline $\begin{array}{c}\text { CF-Fab-VaR } \\
\text { CF-MA- } \\
\text { VaR }\end{array}$ & Carbon & Fabric & Epox & VaRTM \\
\hline $\begin{array}{c}\text { GF-Fab-VaR } \\
\text { GF-MA- } \\
\text { VaR }\end{array}$ & Glass & Fabriti-Axial & Epox & VaRTM \\
\hline $\begin{array}{c}\text { AF2-Fab- } \\
\text { VaR }\end{array}$ & Aramid & Fubric & Epox & VaRTM \\
\hline $\begin{array}{c}\text { AF4-Fab- } \\
\text { VaR }\end{array}$ & Aramid & Fabric & Epox & VaRTM \\
\hline Epoxy-VaR & N.A. & N.A. & Epox & VaRTM \\
\hline $\begin{array}{c}\text { CF-Fab- } \\
\text { Prepreg }\end{array}$ & Carbon & Fabric & Epox & $\begin{array}{c}\text { Prepreg- } \\
\text { Autoclave }\end{array}$ \\
\hline \hline NAB & N.A. & N.A. & $\begin{array}{c}\text { Nickel } \\
\text { Aluminum } \\
\text { Bronze }\end{array}$ & Casting \\
\hline
\end{tabular}

\subsection{Test Equipment for Cavitation Erosion}

Using the magnetostrictive ultrasonic transducer device, we conformed the test conditions to ASTM-G32 $2^{8}$, and carried out an opposed cavitation erosion test ${ }^{9}$. The transducer is shown in Figure 20 and its vibrating frequency and vibration amplitude (peek to peek) were $19.5 \mathrm{kHz}$ and $50 \mu \mathrm{m}$, respectively.

In this device, ultrasonic longitudinal oscillation causes pressure fluctuations to arise at the tip of a vibratory horn immersed in liquid, which in turn gives rise to cavitation. The test condition is shown in Figure 21. For this test, we positioned a test specimen at a distance of $0.5 \mathrm{~mm}$ from the vibratory horn tip, and then caused the cavitation produced by the vibratory horn to collapse on the surface of the test specimen.
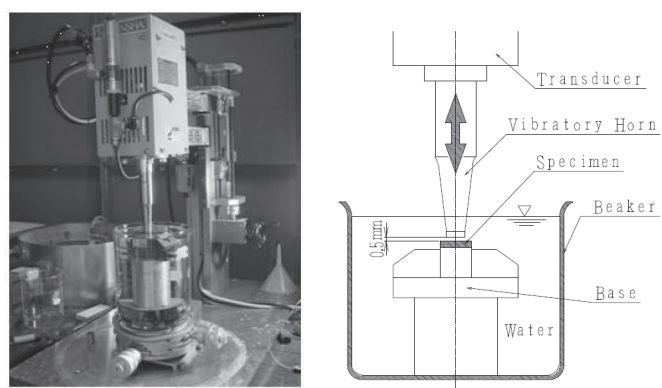

Figure 20 Test Equipment 

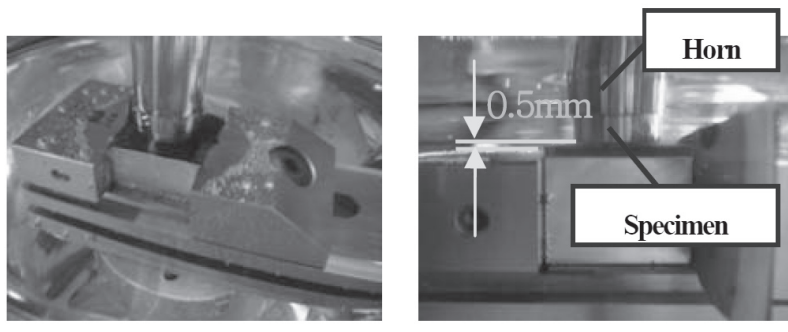

Figure 21 Test condition

\subsection{Test Procedures}

For the positioning conditions of the vibratory horn and the test specimens, the vibratory horn was immersed in the water, and the specimen was placed in a direction counter to the vibratory horn, at a distance of $0.5 \mathrm{~mm}$ from the vibratory horn tip. All of the water used was ion-exchanged water, including the water used to clean the equipment.

The specimens were exposed by cavitation totally for 120 minutes. At every 15 minutes, the mass of the test specimen was measured by a precise mass measurement device, and the surface of the test specimen was subjected to a visual and a microscopic examination (photographed using a digital camera). The fragments of loss material were obtained from the test water by filtering system (mesh size: $0.45 \mu \mathrm{m})$. The filtering system is shown in Figure 22. Due to stirring and the replacement of the water every 15 minutes, the temperature of the water during testing was $21 \pm 4$ degrees Celsius.

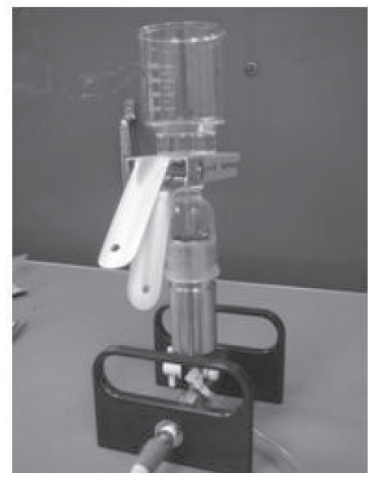

Figure 22 Filtering system

\subsection{Experimental Results}

\subsubsection{Loss Amounts Due to Erosion}

The volume loss due to cavitation erosion of each material with respect to exposure time is shown in Figure 23. The volume losses were determined by dividing the mass loss by the specific gravity. From Figure 23 we can see that for all materials loss amounts increased with time. NAB displayed the smallest loss amounts and even after 120 minutes of test time, there was almost no loss. The composites used in these tests were categorized into four groups according to degree of loss. In order from smallest loss amount, the categories are: Group 1, AF4-Fab-VaR and AF2-Fab-VaR; Group 2, CF-Fab-VaR and Epoxy-VaR; Group 3, CF-MA-VaR, GF-Fab-VaR, and CF-Fab-Prepreg; and Group 4, GF-Fab-VaR, which displayed the most loss amount.

While Group 3 and Group 4 in that epoxy resins were reinforced by GF or CF lost more than about twice as much as Epoxy-VaR, Group 1 in that the resins were also reinforced by AF was stronger than the original epoxy resin of Group 2 in the cavitation erosion. This means AF reinforcement could improve the erosion resistance of epoxy resin, although CF and GF might reduce it.

The loss amounts were difference from combination of the reinforced fibers, the resin, the textile and the fabrication processes. At the first, influence of the textile was considered about as same fiber. In case of CFRPs without CF-Fab-Prepreg, the loss amount for fabric was decreased to approximately 0.6 times of multi-axial. In case of GFRPs, the loss of amount for fabric was increased to approximately 1.5 times of multi-axial. Thus, the loss amounts of GFRPs and CFRPs were reversing with those textiles. It is considered that the influence of the loss amounts is not only the textiles but also other reasons. One of the reasons might be the interface strength between the fibers and the resins. Next is an influence of reinforced fibers as the same textile of fabric. The loss amounts for AFRPs, were the smallest than another FRPs, were made base values. The amounts of $\mathrm{CF}$ and GF were each approximately 2.5 times and 6 times of AFRPs, respectively.

By performing AF lamination on the surface layer using GF-Fab-VaR as the base, which had the poorest erosion resistance, the loss amounts for AFRPs were approximately one sixth of that of GF-Fab-VaR, which is to say that erosion resistance was improved. Regarding the influence of the thickness of the AF layer, we can see that erosion resistance of the AF4-ply material was slightly higher than that of the AF2-ply material. 


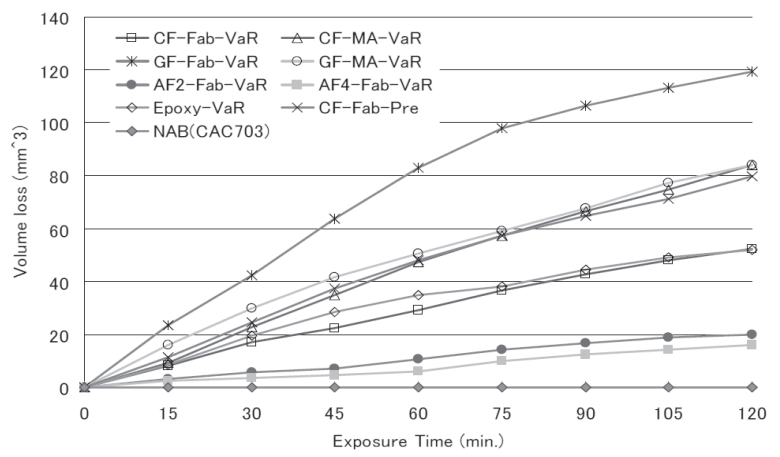

Figure 23 Volume loss for exposure time

\subsubsection{Progress of Cavitation Erosion}

Figure 24 shows photographs of the surface condition of each material, taken every 15 minutes.

For each material, it can be observed that damage is being done in the circular fashion of the vibratory horn tip. Even after 120 minutes had elapsed, NAB was still only slightly roughened. On the other hand, in keeping with the changes in loss amount shown in Figure 23, it can be seen that, for composites, the depth of loss deepened with the exposure time. This loss condition was due to the resin peeling off during the early stages of testing; the cavitation reached to the reinforced fiber, the fibers for CFRPs and GFRPs were broken as each strand disintegrated, and the fibers for AFRPs were curled and remained on the damaged surface. Closer observation is as follows.

Regarding GFRPs, both types lost their surface resin and the fibers themselves were broken, and the collapse surface looked as though it had been scratched out at random, and there was severe unevenness on the surface.

Although the loss rates for CFRPs were different, in all three types corrosion progressed evenly, in the direction of the materials' thickness and for each layer alike.

Both AFRPs whitened and the threads gradually came unraveled; these unraveled threads formed entangled fibrils, which grew ever larger and looked as if they might fall off.

For the loss condition for epoxy resin only, which is a matrix resin, it could be observed that the material whitened, and then particles formed, grew larger, peeled and fell off.

Although this whitening phenomenon was the same as for AFRPs, it can be considered that, because the epoxy is not a fiber, the particles fell off and the loss amount was greater than for AFRPs.

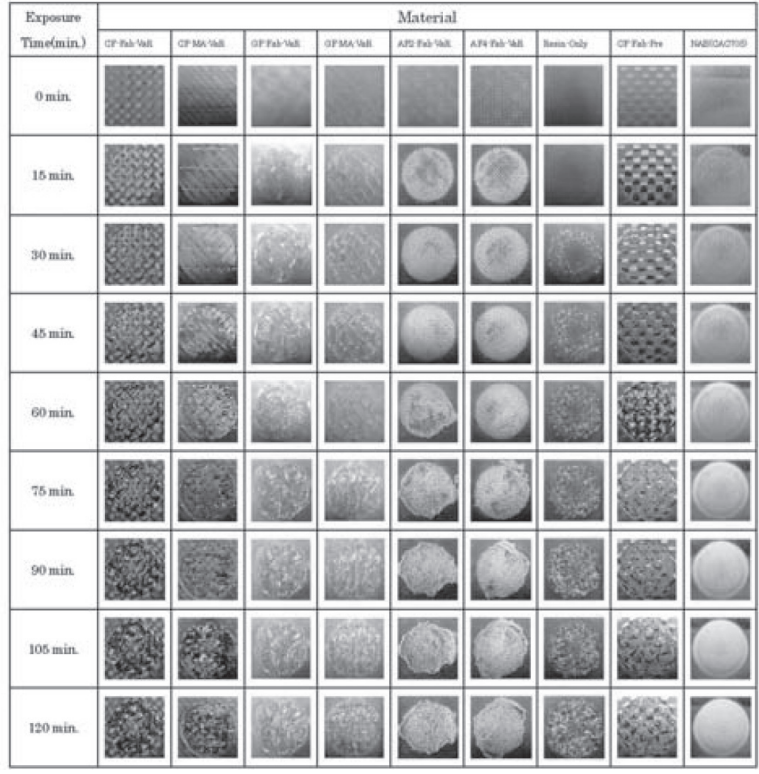

Figure 24 Surface appearance of materials for each time

\subsubsection{Collapse Process for FRP under Cavitation Erosion}

Progress of cavitation erosion for FRP was observed in Figure 24. In this section, we conducted microscope observation to clarify the collapse process for FRP under cavitation erosion, especially for the collapse surface and the peeled fragments of specimens.

Figure 25 shows microphotographs for the collapse surface exposed for 60 minutes and the peeled fragments exposed for between 45 and 60 minutes of epoxy resin-only. Whitish things which were crushed the resin to small were seen in the peeled fragments photos. And also comparatively large particles were observed. Consequently, the collapse process for epoxy resin under cavitation erosion are, at the first whitening phenomenon occurs, gradually collapsed and then particles formed, grew larger, peeled and fell off.

Figure 26 shows microphotographs of CFRPs for the collapse surface exposed for 60 minutes and the peeled fragments exposed for between 45 and 60 minutes. We observed the collapse surface and the peeled fragments in detail by the microscope. For all of CFRPs, it was observed that the peeled fragments were the fibers, the resins and also the fiber bundles with the resins. The size of peeled fragments were approximately $100 \mu \mathrm{m}$ fibers were dominant. The length of peeled fragments of CF-MA-VaR existed over $4 \mathrm{~mm}$ which was longer than the fabric series. On the other hands for GFRPs, Figure 27 shows microphotographs of the collapse surface and the peeled fragments same as condition of Figure 26. Collapse surface photos exhibited both fabric and multi-axial textiles were 
scratched out at random. And the peeled fragments photos showed the fibers and the resins were dominant but the fiber bundles were few. The size of the peeled fragment for fabric and multi-axial textile were similar, furthermore the fragments were divided the fibers and the resin, the length of the fibers were over $1 \mathrm{~mm}$ were dominant. This trend is different from those of CFRPs, the peeled fragments for CFRPs had the fiber bundles a little, but those of GFRPs had hardly the bundles and were mainly longer fibers than CFRPs. Regarding this difference, Figure 28 showed SEM (scanning electron microscopy) photographs for the peeled fragments for CFRPs and GFRPs were observed. It is understood that the adhesive strength between fibers and resins for GFRPs were weaker than those for CFRPs, because the fibers for CFRPs were adhered with the resin mutually, though the fibers of GFRPs were not adhered the resins hardly. It is considered that the peeled fragments of GFRPs disjoined with the fibers. Erosion resistance of CFRPs was superior to that of GFRPs showed in Figure 23. Therefore, it conjectures that erosion resistance is improved when the adhesion between the fiber and the resin are stronger.

Finally, AFRPs showed the strongest erosion resistance among FRPs. Figure 29 also shows the collapsed surfaces and the peeled fragments for AF4-Fab-VaR. The exposure time is same as Figure 26 and 27. The collapse surface and the peeled fragments for AFRPs were different from CFRPs and GFRPs. The surface of AFRP was covered with something like cocoons that were formed entangled fibrils by the observation of the collapse surface. It can be considered that the reason that the loss amounts for AFRPs were less than for the other composite materials was that the fibrils covered over the surface, absorbed the impact waves during cavitation collapse and made it more difficult for loss to progress. The peeled fragments photo shows that the fibers were almost fuzzy and were hardly with a complete form, and also the lump which was entangled the fibers, the fibrils and the resin were able to observe. The lumps fall off during collapse process.

As above mentioned, the method of improving the cavitation erosion resistance for FRP materials is how much can be absorbed the shock wave when the cavitation collapses. The aramid fiber is effective as one of the methods. However, AFRP did not obtain the erosion resistance such as NAB.

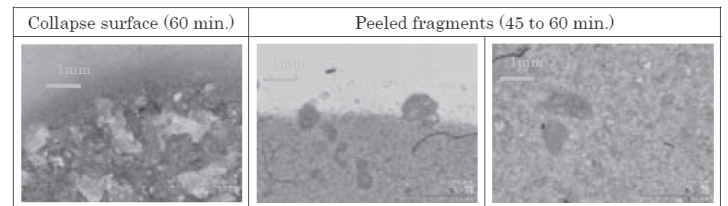

Figure 25 Collapse surface and peeled fragments of Epoxy resin-only by photomicrography

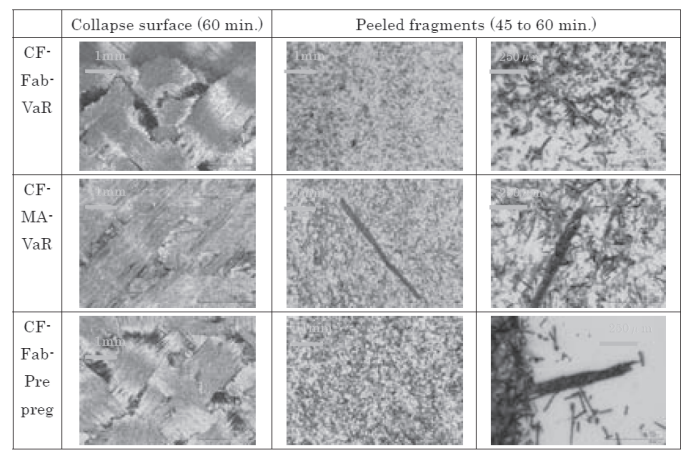

Figure 26 Collapse surfaces and peeled fragments of CFRPs by photomicrography

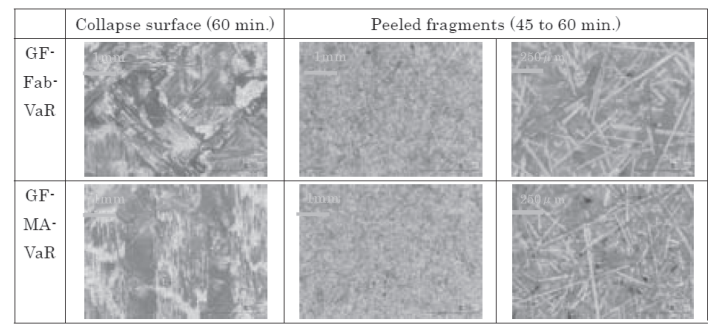

Figure 27 Collapse surfaces and peeled fragments of GFRPs by photomicrography

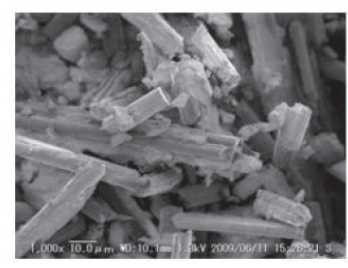

a)CF-Fab-VaR

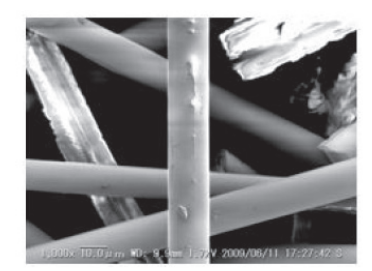

b)GF-Fab-VaR
Figure 28 Peeled fragments of CF and GF bySEM

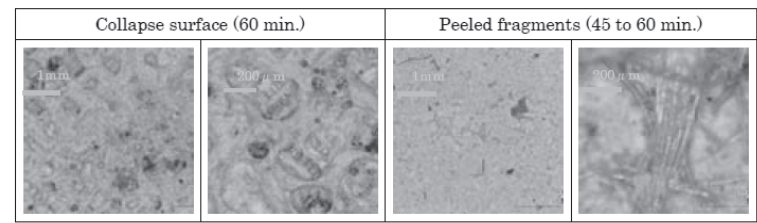

Figure 29 Collapse surface and Peeled fragments of AF4Fab-VaR by photomicrography 


\section{CONCLUSIONS}

In this study, the mechanical property and the cavitation resistance of various composite materials and NAB were investigated to develop composite marine propellers.

In the tensile and bending tests, two types of CFRP specimens were tested, one was made of the prepreg of CF-Fabric and another was made of the prepreg of CF-UD. Both were laminated to be quasi-isotropic. Strength of both Fabric-iso and UD-iso was almost equivalent with that of $\mathrm{NAB}$. In the vibration characteristic tests, the damping ratios in resonance frequency of CFRPs were four times or more than that of NAB.

For the field test using a small fishing boat, two types of CFRP propellers were manufactured by using CF-prepreg. One propeller and another one were laminated CF-Fabric and CF-UD, respectively, to be quasi-isotropic composite. These were a so-called "built-up type" as three CFRP blades were assembled in an NAB boss. The surface of blades was smooth, and the dimension of propellers was in the tolerance of the super-high speed ship. We also manufactured an NAB propeller which was a so-called "mono-block type" to compare with CFRP propellers. In the vibration test, the damping ratios of the both type of CFRP propellers were about ten times larger than that of the NAB propeller.

Cavitation which can cause erosion on the surface is the severe problem for composite propellers. We evaluated the cavitation erosion resistance for eight kinds of FRP and an $\mathrm{NAB}$ in cavitation tests using a magnetostriction ultrasonic transducer.

The cavitation erosion resistance of the NAB was much superior to FRP materials. However, we found that aramid fiber on the surface of FRP can improve the erosion resistance. In order to improve the erosion resistance as the same level as NAB, the further research is necessary.

The propellers made of CFRP will be evaluated regarding the performance and durability by analyzing the result of the field test with the actual ship. We also have a plan to study on the optimal material selection, the designing and the manufacturing for marine composite propellers.

\section{ACKNOWLEGEMENTS}

This study is supported by the subsidy of The Nippon Foundation and Japan Marine Equipment Association.

We would like to thank Dr. I. Ohsawa and Mr. M. Kanai at School of Engineering, The University of Tokyo for the mechanical properties tests. We also thank Dr. A. Sanada and Mr. Y. Tsuji at Industrial Technology Center of Okayama Prefecture for the vibration characteristic test. Thanks are extend to Dr. S. Uematsu and Mr. S. Sugasawa at National Maritime Research Institute, and Ms. N Watanabe at The University of Tokyo for the cavitation test.

\section{REFERENCES}

1) Lee, Y. and Lin, C., "Optimized design of composite propeller", Mechanics of Advanced Materials and Structures Vol. 11(2004), pp 17-30.

2) Lin, H. J. and Lin, J. J., "Strength evaluation of a composite marine propeller", Journal of Reinforced Plastics and Composites Vol. 24, No. 17 (2005), pp 1759-1769.

3) Yin Lu Young; "Hydroelastic Response of Composite Marine Propellers", Propellers/ Shafting 2006 Symposium, SNAME(2006), 7-1-7-7.

4) Benjamin.Y.-H.Chen, Stephen K. Neely, Thad J. Michael, Scott Gowing, Richard P. Szwerc, Dirk Buchler and Reinert Schult; "Design, Fabrication and Testing of PitchAdapting (Flexible) Composite Propellers", Propellers/ Shafting 2006 Symposium, SNAME (2006), 8-1-8-11.

5) Dirk Buchler and Lee Erdman; "Composite Propeller New Features and Properties Specific design and experiences", Propellers/ Shafting 2006 Symposium, SNAME (2006), 9-1-9-6.

6) Yin Lu Young, Michael Motley; "Rate-Dependent Hydroelastic Response of Self-Adaptive Composite Propellers in Fully Wetted and Cavitating Flows", $7^{\text {th }}$ International Symposium on Cavitation(2009), No.60.

7) J. P. Blasques, C. Berggreen and P. Andersen; "HydroElastic Tailoring and Optimization of A Composite Marine Propeller", Composites for Sustainable Progress , ECCM-13(2008)

8) ASTM Designation; "ASTM G32-03", Annual Book of ASTM Standards (2005), pp.106-119.

9) R. Schwetzke and H. Kreye; "Cavitation Erosion of HVOF Coatings", Thermal Sprey: Practical Solutions for Engineering Problems, ASM International (1996), pp.153-158. 